\title{
Assessment of Chemical and Microbiological Quality of Bottled Drinking Water and Evaluation of Accelerated Shelf Life
}

\author{
Amarasena S.V. ${ }^{1 *}$, Perera W.A.J.S. ${ }^{2}$, Karunarathne H. ${ }^{3}$, Liyange S. ${ }^{3}$, \\ Gunawardene D. ${ }^{4}$ \\ ${ }^{1}$ Department of Botany, University of Sri Jayewardenepura, Sri Lanka \\ ${ }^{2}$ Industrial Technology Institute, Sri Lanka \\ ${ }^{3}$ Industrial Technology Institute, Sri Lanka \\ ${ }^{4}$ Department of Botany, University of Sri Jayewardenepura, Sri Lanka \\ *shasheemaamaraena@gmail.com
}

\begin{abstract}
Bottled drinking water was a concept introduced to Sri Lanka in 1980's and new brands are often introduced to the market as it has become a highly moving product so that the health ministry stepped in to the regulation of bottled water and it has become mandatory for the manufacturing companies to register the products under the food act No 26. The specification given in SLSI standards regarding bottled drinking water (SLS 894) can be applied to determine the microbial quality of bottled drinking water just after filling. The SLS specification 894 cannot be applied to determine microbial quality of bottles available in market months after manufacturing. Even though it is very important to consider the consumer's point of view, at the time of consumption, no microbial specification is provided in the standard 894.There is a possibility of chemical and microbial changes occurring within the content of water during its shelf period .One of the main objectives, of the project was to establish a permissible limit for the Total Plate Count (TPC as CFU per ml) at any time of storage. Determination of shelf life by accelerating and incubating samples at an elevated temperature was another objective of the project. Along with the above mentioned objectives a quality evaluation of selected fifteen brands were carried out with relevance to the chemical and microbial parameters. The focused parameters were TPC, fecal Coliforms, Escherichia coli, Algae count, $\mathrm{pH}$, total nitrate, total nitrite, conductivity, Chemical Oxygen Demand (COD), and Free ammonia. Out of the fifteen brands, randomly selected four brands were evaluated according to the Q10 principle to determine the accelerated shelf life. After the incubation period at $42^{0} \mathrm{C}$, all four brands showed a decrease in the CFU compared to the initial counts and $84 \%$ of analyzed chemical parameters were approximate with the initial values. Algae were detected in one of the brands and the same brand exceeded the COD limit $(\max 10 \mathrm{mg} / \mathrm{l})$ after the incubation period. The CFU obtained for the fifteen brands ranged from 36 to 3200 and the permissible CFU range was decided as 87.362 to 1184.170. Around $94 \%$ of the selected brands were within the permissible chemical limits while one of the brands exceeded the COD limit $(10 \mathrm{mg} / \mathrm{l})$. Since most of the chemical parameters were not deviated from the limits stated in SLS 894, it is concluded that microbial parameters are crucial compared to the chemical parameters in the bottled water industry.
\end{abstract}

Keywords: Bottled water, Accelerated shelf life, Permissible limits, Chemical and microbial

Proceedings of the $22^{\text {nd }}$ International Forestry and Environment Symposium 2017 of the Department of Forestry and Environmental Science, University of Sri Jayewardenepura, Sri Lanka 